\title{
Género y experiencias migratorias de adolescentes indígenas mexicanos"
}

\section{Gender and migratory experiences of Mexican indigenous teenagers}

\author{
Oscar Misael Hernández-Hernández ** \\ El Colegio de la Frontera Norte en México, Tijuana, México.
}

Recibido: 3 de marzo de 2018. Aprobado: 25 de abril de 2018 . DOI: 0.25100/lamanzanadeladiscordia.v13i1.6709

Artículo de investigación

Resumen: El objetivo de este trabajo es presentar las experiencias migratorias de adolescentes indigenas mexicanos que fueron repatriados de Estados Unidos, de forma paralela analizar las narrativas de género subyacentes en sus experiencias. A partir de entrevistas realizadas en un albergue para menores migrantes, situado en la frontera norte de Tamaulipas, al noreste de México, se exploran los relatos de nueve adolescentes, de ambos sexos, procedentes de las etnias Purépecha, Mixteca, Nahua y Zapoteca, respectivamente. Con base en sus relatos se identifica que en sus comunidades de origen prevalece una cosmología y organización social moldeada por una estructura de género, asimismo que su decisión de emigrar estuvo matizada por presiones y deseos culturales, y finalmente que su viaje a la frontera se caracterizó por relaciones de poder establecidas con hombres y mujeres mestizas, tales como los coyotes y los migrantes en tránsito. Se concluye que los adolescentes migrantes en su trayecto vivieron una forma de vulnerabilidad étnica al interactuar con mestizos, pero también desplegaron formas sobre ser un hombre o una mujer acorde a su cosmovisión indígena particular.

Palabras clave: Migración; adolescentes; género; etnicidad; poder.
Abstract: The aim of this paper is to present the migration experiences of Mexican indigenous teenagers who were repatriated from the United States, while analyzing the gender narratives underlying their experiences. Interviews were carried out in a shelter for migrant children located on the northern border of Tamaulipas, in northeast Mexico; the stories of nine teenagers, men and women, from the Purépecha, Mixteca, Nahua and Zapoteca ethnicities are explored. Their stories convey cosmologies and social organizations shaped by gender structures; at the same time, it is clear their decision to emigrate was tempered by cultural pressures and desires, while their journeys to the border were marked by power relations established with mestizo men and women such as coyotes and migrants in transit. The paper ends by pointing out that indigenous migrant teenagers experienced forms of ethnic vulnerability in their interactions with mestizos, whereas they deployed ways of being a man or woman according to their particular indigenous worldview.

Keywords: Migration; teenagers; indigenous; gender; power.

*Este artículo presenta resultados parciales de un proyecto titulado: "Migración y repatriación de menores mexicanos desde Estados Unidos", financiado por El Colegio de la Frontera Norte en México, el cual tiene como objetivo captar las trayectorias migratorias de los menores y los riesgos que se viven durante el mismo.

**Profesor e investigador titular en El Colegio de la Frontera Norte, Departamento de Estudios Sociales. Sociólogo por la Universidad Autónoma de Tamaulipas, maestro y doctor en antropología social por El Colegio de Michoacán, México. Sus estudios se enfocan en el análisis de la migración infantil por la frontera noreste de México con el sur de Estados Unidos, específicamente centrado en la violencia y la violación de derechos humanos hacia esta población. Recientemente publicó el libro Migración de menores mexicanos y centroamericanos hacia Estados Unidos de América (2016) y actualmente encabeza un proyecto sobre imaginarios colectivos de la niñez migrante en la frontera México-Guatemala. Fue profesor invitado en la University of Texas at Austin y actualmente es miembro del Sistema Nacional de Investigadores en México. Correo electrónico: ohernandez@colef.mx. 


\section{Introducción}

¿Y cómo nació la idea de ir a Estados Unidos?, le pregunté a Carmelo, un adolescente migrante de 16 años, procedente de un pueblo del estado de Guerrero. "Pues por ver ahí en la casa [que hacía] falta dinero. $\mathrm{Y}$ este así me surgió la idea, como llegan paisanos para allá y hacen sus casas, tienen sus carros", me respondió. La respuesta de Carmelo sobre la necesidad (material y simbólica) como argumento de la migración transnacional, es similar a las de otros adolescentes mexicanos que han sido repatriados de Estados Unidos y después remitidos temporalmente a albergues en la frontera.

Durante la conversación con Carmelo, él narró cómo junto a otros/as migrantes y con la guía de un coyote que los maltrataba, cruzó el río Bravo; cómo durante horas los mantuvieron encerrados en casas de seguridad, con la comida limitada; así como los días y horas que caminaron, hasta el momento en que la migra los agarró y los regresó. El caso de Carmelo no es el único. Martha, una adolescente de Oaxaca, de 14 años, comentó que ella decidió emigrar a Estados Unidos, "porque en la casa me quedé con mi abuela y mi mamá, y no había pa'1 gasto, así que quise venir a buscar a mi papá en el otro lado, aunque mi familia no quería, porque se veía mal que yo saliera y era peligroso". Y al menos para Martha lo fue, no sólo porque la detuvo la migra, sino también porque al llegar a la frontera un hombre quiso llevarla a la fuerza diciendo que él la cruzaría.

Los casos de Carmelo y Martha remiten a la migración transnacional de adolescentes mexicanos indígenas, el primero de la etnia nahua y la segunda mixteca. En general, se trata de un fenómeno complejo que alude al tránsito poblacional de un país a otro, pero que, en el contexto de la globalización económica y cultural, como plantea Pries (2002), tiene causas multivariables y se caracteriza por el uso de diferentes medios de tránsito para "perforar" las fronteras de los Estados-nación. De forma específica, sus narrativas evidencian lo que Ruiz (2001) llamó "los riesgos de cruzar" las fronteras, particularmente para grupos vulnerables como son los denominados menores migrantes no acompañados, quienes enfrentan riesgos y peligros antes y después de cruzar la frontera (Moctezuma, 2014).
Este artículo explora las experiencias migratorias de algunos adolescentes indígenas mexicanos que cruzaron la frontera México-Estados Unidos, pero que fueron detenidos y repatriados por agentes de la Border Patrol. Se conciben como adolescentes, porque oscilaban entre los 14 y 17 años, pero, sobre todo, porque se encontraban en una etapa de cambios corporales y redefiniciones psicosociales (Weissmann, 2005). Asimismo, se denominan indígenas, porque provenían de grupos étnicos del sur y centro-occidente de México, pero, sobre todo, porque se identificaban como tales.

De forma particular, en este artículo interesa analizar e interpretar las narrativas de género subyacentes en las experiencias migratorias de los/ las adolescentes indígenas entrevistados/as. Lo anterior se debe a que gran parte de los estudios sobre migración transnacional de adolescentes mexicanos se han centrado en los procesos, las instituciones y las políticas migratorias (Chávez y Menjívar, 2010), así como en la vulnerabilidad de éstos en su tránsito (Ariza 2014), más no distinguen diferencias étnicas, ni han privilegiado el género como perspectiva de análisis para entender sus experiencias migratorias, ya sean mestizos o indígenas. No en balde, en un balance relativamente reciente, Hondagneu-Sotelo (2011) afirma que el área de estudio que articula género, migración y niñez constituye "Un área desarrollada poco cohesivamente en comparación con otras áreas". Asimismo, señala que, "la investigación sobre la niñez y las ramificaciones de género en la migración transnacional, es un campo emergente crítico" (p. 227).

Tanto la limitada producción de estudios sobre adolescentes indígenas mexicanos que han emigrado a Estados Unidos, así como el análisis de sus experiencias desde alguna perspectiva de género, constituyen parte de las motivaciones del presente trabajo. Por otro lado, coincido con Díaz-Cervantes (2014) respecto a la necesidad de explorar las articulaciones entre etnicidad y género para comprender "la construcción del sujeto indígena contemporáneo", aunque sin caer en romanticismos étnicos o esencialismos que aludan a tipos o modelos indígenas de género.

¿De qué formas las experiencias migratorias de los adolescentes indígenas develan narrativas de género 
que hacen visible la construcción, cuestionamiento y redefinición de sujetos particulares? Este trabajo constituye un esfuerzo por responder dicha interrogante centrándose en los relatos de nueve adolescentes indígenas entrevistados/as en la frontera de Tamaulipas, al noreste de México, en el marco de un proyecto de investigación que exploró la construcción del género y la masculinidad en la migración de menores de edad que han sido repatriados de Estados Unidos (HernándezHernánez, 2012). Se trata de una primera incursión que no intenta generalizar, sino más bien mostrar algunos indicios de cómo se construye, cuestiona o redefine el género en las experiencias migratorias de algunos adolescentes indígenas de México.

\section{Puntos de partida teóricos}

"Mientras los estudios sobre migraciones internacionales son cada día más amplios y numerosos y buscan introducir una importante discusión teórica", señalaron Torres y Carrasco (2008, p. 10) hace casi una década, en un estudio sobre la migración indígena en América Latina, "la escasez de estudios que se refieren a la movilidad de los grupos indígenas cuestiona tanto a la producción de conocimiento como a la generación de políticas públicas por la ausencia de incorporación de las variables étnico-culturales en los análisis y en las acciones concretas" (p. 10).

La observación de los autores obviamente es una crítica teórica y política. Su énfasis en lo étnicocultural de la migración tiene gran relevancia al considerarlo una dimensión identitaria de los flujos migratorios indígenas, no obstante, dejaron de lado otras igual de importantes como son las identidades de género. En parte este es el caso de la literatura sobre adolescentes indígenas migrantes en México, en especial de los que proceden del sur, la cual no sólo es limitada en su producción, sino también carece de alguna perspectiva de género, aunque hay sus excepciones.

El trabajo de Villanueva y García (2008), aborda las causas de la migración internacional entre la población de Chiapas y plantea que entre éstas se encuentran la crisis del desarrollo agropecuario y los fenómenos naturales. No obstante, también agregan que, "la migración ha venido a desestructurar las antiguas relaciones y formas de organización social para dar cabida a la formación de redes para favorecer la movilidad de la población" (2008, p. 53). Esto último es relevante, pues evidentemente no sólo tienen que ver fenómenos estructurales, sino también identitarios.

Al respecto, los estudios de Aquino (2009; 2012) ilustran cómo la decisión de emigrar a Estados Unidos por parte de algunos adolescentes indígenas zapatistas de Chiapas, no sólo plantea un dilema en torno a lo que la autora denomina la "lógica militante" versus la "lógica migrante", sino también cuestiona a los adolescentes como hombres responsables hacia la comunidad y la familia, pero sobre todo, como hombres que no cumplirán con su rol de proveedores y procreadores, pues "para cualquier comunidad indígena, la pérdida de su población masculina en edad productiva constituye una grave amenaza para su reproducción" (2009, p. 11). Las mujeres, al menos en estas lógicas, siguen siendo remitidas al ámbito privado de la reproducción.

Por último, las reflexiones de Cruz (2015) en torno a las experiencias de adolescentes tzeltales y choles que emigraron a California, Estados Unidos, no sólo ponen de relieve las causas de este fenómeno en términos del impacto de políticas neoliberales, sino también los dilemas que viven dichos jóvenes al tener "la voluntad de pertenencia a los grupos étnicos, el interés de algunos por mejorar la economía de sus ejidos invirtiendo en negocios y potreros; el desinterés por dar continuidad a la vida campesina y tradicional, la postergación del matrimonio, el retraso de la procreación así como la evasión de compromisos y la tendencia a la exogamia" (p. 217).

Como se observa, los trabajos descritos muestran la migración transnacional de adolescentes indígenas de México como resultado de fenómenos estructurales, pero por otro lado, también contienen indicios de que se trata de un proceso subjetivo en el que cosmovisiones étnicas y culturales se traslapan y ponen de relieve la construcción de la masculinidad entre los adolescentes con relación a su comunidad, la familia e incluso en el marco de cambios generacionales y relaciones transnacionales, tal como lo muestran otras investigaciones llevadas a cabo con 
mixtecos (Hernández, 2008; Smith, 2006) y nahuas (Martínez, 2010).

Esta situación pone a debate cómo analizar las experiencias migratorias de adolescentes indígenas mexicanos desde alguna perspectiva de género. Ante la carencia de enfoques conceptuales que articulen la construcción del género entre indígenas migrantes, aquí se echará mano de un tipo de hibridismo teórico al conjugar los clásicos (pero aún útiles) planteamientos de Scott (1996) sobre el género como construcción de la diferencia sexual basada en relaciones de poder, y de Connell (1997) en torno al género como una forma de ordenamiento de la práctica social.

Para iniciar, hay que destacar que Joan Scott no sólo es una autora conocida por su propuesta de incluir el género como categoría en los análisis históricos, sino también, o especialmente, porque elaboró y planteó una noción del género que, en su opinión, tenía dos definiciones articuladas entre sí. Aunque su propuesta y noción data de mediados de la década de los ochenta, sigue siendo vigente y útil en los estudios de género orientados a diferentes temáticas, aunque debatible. Para ella:

El género es un elemento constitutivo de las relaciones sociales basadas en las diferencias que distinguen los sexos y el género es una forma primaria de relaciones significantes de poder, pero la dirección del cambio no es necesariamente en un solo sentido. Como elemento constitutivo de las relaciones sociales basadas en las diferencias percibidas entre los sexos, el género comprende cuatro elementos interrelacionados (Scott, 1996, p. 291).

La utilización de la definición de Scott como ejemplo, no sólo se debe a lo ya señalado, sino también a que, como ha afirmado Castellanos (2003), "la definición de Scott ha adquirido gran importancia en los estudios de género, pues a ella le debemos el concepto de la transversalidad del género, es decir, la omnipresencia de este elemento cultural" (p. 42). Por supuesto, la definición de esta autora no es la única, pues le preceden y rodean otras, no obstante, desde mi perspectiva es una de las más precisas a pesar de las críticas sobre sus limitaciones (De Barbieri, 1995).
En la definición de Scott (1996), el género es una construcción social sobre las diferencias sexuales, es decir, sobre lo que significa ser un hombre o una mujer; además, enfatiza que dicha construcción se hace visible en las relaciones sociales, las cuales son, en gran parte, relaciones de poder; todo lo anterior visible a través de símbolos, normatividades, políticas, instituciones y en la identidad misma. Aunque la propuesta de Scott no consideró la dimensión étnica, sigue siendo útil para explorar y comprender las diferencias sexuales entre hombres y mujeres, incluso entre hombres o entre mujeres, como pueden ser los o las adolescentes indígenas migrantes.

Por otro lado, el concepto de género propuesto por Connell (1997) lo define como "una forma de ordenamiento de la práctica social" y esta última, según el autor, "responde a situaciones particulares y se genera dentro de estructuras definidas de relaciones sociales. Las relaciones de género, las relaciones entre personas y grupos organizados en el escenario reproductivo forman una de las estructuras principales de todas las sociedades documentadas" (p. 35). Es justamente en esta articulación entre la práctica social y la estructura cuando se configuran prácticas de género, como la masculinidad.

Para Connell (1997), cuando se comprende cómo se configuran tales prácticas de género, es cuando se logra comprender la estructura de género, la cual en su opinión, se compone de tres dimensiones: relaciones de poder, en especial las que aluden a las asimetrías entre hombres y mujeres, pero también entre los propios hombres; relaciones de producción o división genérica del trabajo en el marco de procesos económicos y culturales; relaciones de cathexis, las cuales no se limitan a meros deseos sexuales, sino también al despliegue de emociones cuanto se interactúa con un objeto, con sujetos particulares o situaciones específicas donde se pone a prueba la masculinidad o la feminidad.

Los planteamientos de Connell en torno al género como ordenamiento de la práctica social y como una estructura que incluye tres dimensiones, son elementos de análisis útiles para explorar la estructura de género que permea en las comunidades de origen de los adolescentes indígenas, pero sobre todo, para comprender cómo aspectos étnicoculturales sentaron las bases para la migración de 
los éstos y, simultáneamente, para la configuración de la masculinidad entre ellos, en tanto ideologías y prácticas en torno a ser un hombre, o actuar como tal, en especial en el trayecto migratorio.

\section{Metodología}

Con base en los antecedentes y referentes teóricos antes planteados, aquí se presentan y analizan las experiencias migratorias y narrativas de género de nueve adolescentes indígenas mexicanos que de forma irregular cruzaron a Estados Unidos, pero fueron detenidos por la Patrulla Fronteriza y repatriados a México por el norte de Tamaulipas. Los adolescentes fueron entrevistados en el marco de un proyecto sobre la violación de derechos de menores migrantes mexicanos no acompañados, que fueron repatriados por la frontera de Tamaulipas, al noreste de México y sur de Texas. Se trató de una investigación de tipo exploratorio-descriptivo dado que poco se conocía del objeto de estudio y derivado de los primeros hallazgos, se delinearon otros ejes de análisis (Díaz y Calzadilla, 2016), entre estos últimos el de conocer las experiencias migratorias de adolescentes indígenas.

El proyecto se llevó a cabo en el verano del 2015, específicamente en Centros de Atención a Menores Fronterizos (CAMEF por sus siglas), que son albergues para menores migrantes mexicanos que han sido repatriados de Estados Unidos. En el caso de la frontera de Tamaulipas, actualmente existen tres CAMEF y éstos se sitúan en las ciudades de Matamoros, Reynosa y Nuevo Laredo. Durante el desarrollo del proyecto, el cual se basó en una encuesta aleatoria a menores migrantes repatriados, en el CAMEF situado en Matamoros identificamos la presencia de algunos adolescentes indígenas, a quienes nos propusimos entrevistar, usando un guión de entrevista predefinido, para conocer sus experiencias migratorias.

Después de solicitar permiso a las autoridades del CAMEF para proceder con las entrevistas, solamente logramos entrevistar a nueve adolescentes indígenas. Ello se debió a dos razones: 1) la entrevista era voluntaria y muchos de los adolescentes no aceptaron compartir sus experiencias, y 2) su estancia en el CAMEF fue corta debido a que familiares o autoridades de sus lugares de origen fueron por ellos de inmediato. Los/las adolescentes que fueron entrevistados/ as eran 6 varones y 3 mujeres, de entre 14 y 17 años y pertenecían a las etnias Purépecha (dos de Michoacán), Mixteca (dos de Oaxaca), Nahua (uno de Guerrero y otro de Puebla) y Zapoteca (tres de Oaxaca) (ver Tabla 1). En conjunto, procedían de comunidades indígenas caracterizadas por familias extensas y pobres, dedicadas al trabajo agropecuario de subsistencia que alternaban con algunos oficios. Específicamente se trataba de adolescentes que se asumían como indígenas, que hablaban español y sólo en dos casos manifestaron hablar su lengua.

Tabla 1. Adolescentes migrantes entrevistados según etnia y sexo.

\begin{tabular}{lcc}
\hline Etnia & Varones & Mujeres \\
\hline Purépecha & 1 & 1 \\
Mixteca & 1 & 1 \\
Nahua & 2 & 0 \\
Zapoteca & 2 & 1 \\
Total & 6 & 3 \\
\hline
\end{tabular}

Fuente: Proyecto "Violación de derechos humanos de menores migrantes no acompañados en la frontera de

Tamaulipas”, 2015.

Para entrevistarlos, como antes se dijo, se utilizó un guión, el cual además de ejes de exploración como datos sociodemográficos, el lugar de origen, la decisión de emigrar y demás, también incluyó indagaciones sobre la cultura en sus comunidades, los riesgos que vivieron al migrar, las emociones que experimentaron, entre otros aspectos. Las entrevistas se llevaron a cabo en las instalaciones del CAMEF, particularmente en el comedor; espacio donde todos accedieron a hablar de sus experiencias. Finalmente, cabe resaltar que las entrevistas se llevaron a cabo durante medio mes, pues los adolescentes no siempre querían dialogar, incluso, en algunas ocasiones no fue posible grabarlas, sino sólo tomar notas, debido a que ellos argumentaban que les daba "pena" que su voz se grabara.

Las experiencias migratorias de los y las adolescentes (Abel, Lucio, Gerardo, Carmelo, Rogelio, José, Martha, Lucía y Tomasa, todos seudónimos) fueron recopiladas a través de entrevistas grabadas 
o reconstruidas mediante notas de campo, sin embargo, la estrategia para entrevistarlos o conocer sus experiencias en sí abrevó de la técnica conocida como relato de vida. Con base en Bertaux (2005), dicha técnica se consideró como una forma de entrevista narrativa que inicia "desde el momento en que un sujeto cuenta a otra persona, investigador o no, un episodio cualquiera de su experiencia vivida" (p. 36), destacándose significados, pero también referentes en tanto relaciones, procesos y normas socialmente construidas. El relato de vida, entonces, fue útil como recurso para reconstruir sólo algunas de las experiencias migratorias de los adolescentes. Incluso, no sólo sus experiencias, sino también sus emociones y estados de ánimo al entrevistarlos, pues algunos resaltaban más su "pena" de hablar de sus experiencias, mientras que otros enfatizaban su "pena" de no haber logrado llegar a trabajar en Estados Unidos y regresar a sus comunidades.

Desde esta perspectiva, las experiencias de los y las adolescentes indígenas, captadas a través de las entrevistas fueron concebidas como un medio para conocer $-\mathrm{y}$ reconstruir- sus relatos migratorios y, simultáneamente, las narrativas de género subyacentes. Si bien se cuestiona que "la intervención del transcriptor" puede convertirse en la "ficcionalización" de los hechos (Randall, 1992), las experiencias de los y las adolescentes, recopiladas a través de esta técnica, han sido contextualizadas para captar los significados sobre ser un hombre o una mujer en sus comunidades de origen, así como en el trayecto migratorio.

\section{La estructura de género en las comunidades indígenas}

El análisis de los flujos migratorios de indígenas del sur de México ha puesto de relieve tanto la migración interna como transnacional, así como los procesos de cambio y adaptación cultural en torno a la identidad étnica (Nolasco y Rubio, 2005). Sin embargo, como se ha señalado, poco o nada se sabe acerca de cómo los contextos étnico-culturales donde residen los indígenas, particularmente los adolescentes, incorporan elementos autóctonos de construcción del género, los cuales pueden incidir en la decisión de emigrar, más allá de la pobreza y la marginación.
Lo anterior da pie para pensar cómo se conforma la estructura de género en las comunidades de los adolescentes indígenas, específicamente las relaciones de poder, de producción y de cathexis que subyacen. En general, como se dijo antes, los adolescentes entrevistados proceden de etnias como son la Purépecha, la Mixteca, la Nahua y la Zapoteca, las cuales se asientan en comunidades rurales de Puebla, Michoacán, Oaxaca y Guerrero; etnias que, si bien existen cosmovisiones particulares, "comparten muchos elementos esenciales", como ha señalado Navarrete (2008).

Según el mismo autor, "casi todos los pueblos consideran que los seres de este mundo tienen elementos, o fuerzas, calientes y fríos" (2008, p. 78). Entre los primeros se encuentran los relacionados con el sol, los varones, la luz y la vida, mientras que los segundos con la luna, las mujeres, la oscuridad y la muerte. Claramente se trata de un binomio cultural que puede variar, no obstante, da pistas al menos sobre las relaciones de poder y de producción, entre hombres y mujeres, que prevalecen en algunas comunidades indígenas de esta región del país.

Las danzas que se celebran en algunos pueblos de donde proceden los jóvenes entrevistados son un ejemplo de lo anterior. Al respecto, Abel, un joven náhuatl de 17 años, procedente de Vicente Guerrero, Puebla, comentaba que en su pueblo se celebraba la fiesta de los tecuanes (tecuanis, en náhuatl), en la que unos hombres van a cazar a un tigre que hace daño a sus cultivos, pero luego son dañados y una mujer los atiende. Esta danza, al igual que otras, incorpora un conjunto de simbolismos en torno a las alianzas interétnicas y el trabajo comunitario (Maturano, 2010), pero también devela cosmovisiones de género: los hombres cazan, las mujeres curan.

O bien la danza de la pluma, la cual mencionaron tanto Gerardo como Rogelio, ambos de 16 años, ambos zapotecos procedentes de Santiago Matatlán, Oaxaca. Ellos comentaron que dicha danza duraba mucho y que salían bailando Cortés y la Malinche, así como el rey azteca y su señora. Nuevamente, se reflejan simbolismos en torno a la conquista y colonización, pero también sobre el predominio de los hombres en lo público y el de las mujeres como sujetos genéricos secundarios, lo cual en parte explica la prevalencia de un sistema de género 
jerárquico y dicotómico que existe aún en algunas comunidades zapotecas (Stephen, 2002).

Más allá de las cosmovisiones étnico-culturales en algunas comunidades de las que son oriundos algunos adolescentes entrevistados, hoy en día tanto las relaciones de poder como de producción son claramente matizadas por la valoración de los hombres y su masculinidad, por encima de las mujeres y la feminidad. Por ejemplo, Lucio, un adolescente purépecha de 16 años, originario de Cherán, Michoacán, al preguntarle de qué vivía su familia en el pueblo, él narró lo siguiente:

Nosotros tenemos una parcela para sembrar y otro pedazo de tierra con árboles. Ahí mi papá y mi hermano mayor trabajan y me llevaban a mí cuando salía de la escuela. Eso hacían ellos, sembrar maíz, frijol, y a veces cortaban madera. Nos llevaba mi papá, sí, pero pues era duro, a mí no me gustaba andar en el sol, pero pues así era, entonces no había dinero y como tengo un hermano en Carolina que lo invitaron amigos de aquí a irse, él me dijo que si quería irme y por eso me vine, pero no alcanzaba. Mi mamá nomás en la casa, ella no trabajaba, a veces ayudaba a nosotros en la parcela, pero casi no porque mi papá no le gustaba, le decía que se asoleaba y que para qué andaba fuera de la casa. Entonces como no alcanzaba el dinero, pues me vine y mi hermano me mandó poco dinero, porque tiene poco allá ("Lucio", comunicación personal, 2015).

Mientras que Martha, la adolescente mixteca de 14 años, procedente de Oaxaca, comentaba al respecto:

Cuando estaba mi papá en el pueblo, pues él trabajaba en lo que salía y mi mamá y mi hermano y yo, en la casa. Ya esperábamos que él regresara, pero pues yo iba a la escuela, luego que regresaba pues a ayudarle a mi mamá en la casa, porque había que hacer la comida, la casa; a veces también mi abuela iba o yo iba con ella, y me ponía a ayudarle. Yo le decía a mis papás que quería trabajar verdad, porque yo veía que no alcanzaba, pero mi papá me decía que no, que estudiara, y que le ayudara a mi mamá en la casa, que ahí tenía mi trabajo, pero ya después él se fue al norte, y no sabemos de él, nomás que se fue a Austin, pero ya no supimos, entonces fue que yo quise buscarlo pues, aunque mi mamá y mi abuela no querían ("Martha", comunicación personal, 2015).
Las narrativas de Lucio y Martha, además de dar pistas sobre algunas de las rutas y redes que eligen migrantes purépechas o mixtecos en Estados Unidos (Tomás, 2013), también da cuenta de la organización social familiar en términos de ideologías y relaciones de género, pero, sobre todo, de la división sexual del trabajo. Tal parece que predomina lo que Núñez (2007), aunque para otro contexto y grupo social, ha identificado con un vínculo de pareja en adultos mayores, que se caracteriza por el binomio atender/mantener; en el primer caso las mujeres "atienden" a los hombres, $\mathrm{y}$ en el segundo los hombres "mantienen" a las mujeres. En otras palabras, los hombres dominan lo público y las mujeres se remiten a lo privado.

Esta situación, además, es muy similar a lo que ha documentado Stern (1999) para el caso de algunos pueblos indígenas de Morelos y Oaxaca en las postrimerías del periodo colonial. Cuando Lucio menciona que a su padre no le gustaba que su madre no fuera a "ayudar" en la parcela porque "se asoleaba" y "andaba fuera de la casa", parece ser que no sólo se marca una clara división sexual del trabajo y dominación del varón para decidir cómo se organiza su familia, sino también lo que Stern llamó un tipo de patriarcado que controla los movimientos corporales y despliegues sexuales de las mujeres. De igual forma se percibe en el relato de Martha: su socialización de género en actividades supuestamente de mujeres como los quehaceres del hogar.

Además de lo anterior, en el relato también se identifica otro proceso subjetivo que en parte permite comprender cómo se enseña a la niñez a ser hombres o mujeres, en otras palabras, la construcción y socialización de género desde el ámbito familiar y a través del trabajo. La práctica del padre de Lucio de llevar a sus dos hijos a la parcela no sólo puede entenderse como el uso de mano de obra para optimizar tiempo, trabajo y esfuerzo en el marco de una economía neoliberal que ha subsumido a los pueblos indígenas en la pobreza (Villanueva y García, 2008), sino también como parte de un aprendizaje de la masculinidad a partir de comportamientos observados y de factores culturales que refuerzan el sentido de lo varonil (Askew y Ross, 1991). De igual manera, el discurso 
del padre de Martha respecto a que en la casa tenía el trabajo, marcaba y legitimaba la frontera de género respecto al espacio público para los hombres y el privado para las mujeres.

Las narrativas de otros adolescentes indígenas son muy similares a las de Lucio o Martha. Por ejemplo, José, un joven mixteco de 17 años, nativo de San Antonino Monteverde, Oaxaca, comentaba que en su pueblo su madre era la dueña de una parcela que le heredó su abuelo, pero que era su padre quien la trabajaba:

\begin{abstract}
Mi abuelo le dejó una parcela a mi mamá para que sembrara, pero pues ella no podía, así que mi papá trabajaba la tierra, y ella estaba con mis hermanos, tengo dos menores que yo y una hermana mayor que ya se casó. Ella se dedicaba a la casa y mi papá era el que trabajaba, pero luego el dinero ya no alcanzó porque para el estudio y la comida, entonces quise venirme, más porque luego mi papá se separó de mi mamá y no alcanzaba (“José", comunicación personal, 2015).
\end{abstract}

Mientras que Tomasa, una adolescente zapoteca de 15 años, procedente de un pueblo también de Oaxaca, cercano a Guerrero, también aludía a esta socialización de género en tanto un proceso subjetivo que inicia desde la infancia. Ella narraba al respecto: "Nosotros allá en el pueblo hacíamos artesanías, ollas y tasas, mi mamá y mis hermanas trabajábamos en eso; también trabajábamos en la tierra, pero eso lo hacía mi papá con mi hermano mayor, pero ellos hacían más de eso, que decían que porque nosotras teníamos las manos delicadas y ellos con callos en las manos, que no aguantábamos".

Los relatos de José y Tomasa, como se observa, también muestran el viejo sistema sexo-género que asocia a los hombres en lo público del trabajo remunerado y a las mujeres en lo privado de la casa $\mathrm{y}$, por consiguiente, de las actividades domésticas, incluso con actividades productivas, pero con un matiz supuestamente femenino. Por otro lado, también contiene un elemento simbólico importante que deja entrever el por qué algunos adolescentes indígenas decidieron emigrar a Estados Unidos: ante la ausencia de un referente masculino como es el padre, los hijos varones intentan desempeñarse como proveedores y responsables buscando alter- nativas laborales en otros contextos, como mostró un estudio realizado en la región otomí-tepehua de Hidalgo (Ramírez, Gutiérrez, Valladares y Gutiérrez, S.f.). Sin embargo, la ausencia del padre y las carencias económicas no son las únicas explicaciones de la emigración de los varones, sino también de las mujeres, como se mostrará enseguida.

\section{La cathexis de migrar o la presión/deseo de ir al norte}

Hasta ahora, en parte se ha mostrado cuál es la estructura de género que predomina en las comunidades de origen de los jóvenes indígenas entrevistados. Se trató de una exploración superficial de la cosmovisión tradicional que de cierta forma define ideologías y relaciones de género contemporáneas, pero también de una exploración que con base en los relatos y las narrativas de los propios adolescentes; mostró el tipo de relaciones de poder y de producción que conforman la estructura de género y que, al menos en las familias de algunos de ellos, definen los vínculos entre hombres $\mathrm{y}$ mujeres a través de una socialización de género a nivel familiar y comunitario.

Dicha estructura de género, como se afirmó, no sólo ha devenido en una supuesta dominación masculina basada en la división sexual del trabajo y el control de los movimientos y despliegues corporales de las mujeres, sino también en un proceso de aprendizaje masculino y femenino, a través de la socialización, en el ámbito laboral comunitario. Sin embargo, queda pendiente analizar la otra dimensión de la estructura de género, a decir de las relaciones de cathexis, que, si bien aluden al deseo y a las emociones en términos generales, aquí las abordaré en tanto formas de presión/deseo cultural para emigrar a Estados Unidos y, de esta forma, forjar identidades de género.

Regresemos con José: cuando él narró que quiso emigrar porque el dinero no alcanzaba en su casa $\mathrm{y}$, posteriormente, su padre se separó de su madre, matizó la presión que sintió de ser él quien tendría que desempeñarse como el proveedor económico de la familia y el deseo de lograrlo emigrando a Estados Unidos; el hecho de tener dos hermanos menores que él, una hermana mayor pero ya casada y una madre sin esposo, se convirtieron en el binomio presión/ 
deseo para emigrar. Por supuesto, no se trata de algo exclusivo de los adolescentes indígenas, pues también entre adolescentes mestizos se ha mostrado dicha situación, pero de igual forma se trata de ritos de paso en la construcción de identidades de género (Huacuz y Barragán, 2008).

Sin embargo, al menos en algunos pueblos indígenas, las representaciones sobre ser un hombre o una mujer se articulan con lógicas particulares en cuanto al género y la etnia. Por ejemplo, en su brillante etnografía sobre los tojolabales de Chiapas, López (2010) mostró que entre esta etnia los hombres, para ser considerados como tales, debían "tener cabal el pensamiento de hombre", por un lado, y "tener cabal el cuerpo de hombre". La primera noción refiere asumir la representación de la familia, mediar ante la sociedad y tener capacidad de mando, mientras que la segunda se refiere a demostrar ser heterosexual, cortejar mujeres, pero también procrear.

Claramente, almenosen comunidades tojolabales, las nociones de ser un hombre con relación a la cabalidad del pensamiento o del cuerpo, implican que todo lo contrario es asociado con lo femenino, es decir, las mujeres no representan a la familia, sino que están subsumidas al poder de un jefe de familia; las mujeres no mandan, obedecen; las mujeres son heterosexuales, pero su cuerpo y sexualidad debe ser controlada por los varones, cortejar es un tabú y la procreación es un proceso biológico sobre el que ellas no necesariamente deciden al estar subsumidas a la autoridad masculina.

Por supuesto, en comunidades y pueblos nahuas, mixtecos, purépechas o zapotecas, la alusión a "tener cabal el pensamiento o el cuerpo de hombre" no existen, en tanto que son categorías analíticas. Sin embargo, los significados y matices de éstas eran evidentes en los relatos y narrativas de los adolescentes indígenas entrevistados. Recordemos que Carmelo, el joven nahua de Guerrero, señaló que su decisión de emigrar fue porque él veía que en su casa faltaba dinero -al igual que lo expresaron Lucio y José-, pero también porque él veía cómo llegaban paisanos que construían o traían propiedades. Sin embargo, Carmelo también comentó algo más sobre su decisión de emigrar:
Allá en el pueblo pues no había dinero, lo que mi papá sembraba a veces vendía, pero también para comer. Luego un día me dijo que ya se le hacía difícil que yo fuera a la escuela, yo estaba en la preparatoria allá en Temalacatzingo, entonces tuve que salirme para ayudarle a trabajar a él y que mis hermanas fueran a la primaria. Unos amigos de ahí me dijeron: "¿Qué, nos vamos al norte o tienes miedo?", pero yo no quería al principio, y le dije a mi mamá y dijo: "No, que vas a hacer, es peligroso", pero mi papá decía: "Pues yo ya no puedo trabajar mucho y falta dinero". Entonces pensé que si quería ayudarlos pues tenía que irme y más si luego yo quería hacer una casa y tener mi familia, ¿verdad?, porque por ahí traigo una novia. Ya les dije a mis amigos: "Pues nos vamos". Y me vine con dos de allá que ya tenían conocidos acá, pero nos agarraron al cruzar. Yo ya me hacía que trabajaba y mandaba dinero para hacer mi casa y para ayudar a mis papás, como le hacen otros que se van, pero pues no se pudo (“Carmelo", comunicación personal, 2015).

En el relato de Carmelo hay algunos indicios en torno a lo que también podría denominarse la formación de hombres con "pensamiento" y "cuerpo cabal", similar a los tojolabales de Chiapas, aunque en este caso remitido a un pueblo nahua de Guerrero: primero, la presión de asumir la proveeduría económica de su familia; segundo, su capacidad de decisión de emigrar a pesar de la resistencia de la madre y ante la coacción simbólica del padre; tercero, su énfasis en ser heterosexual al traer una novia; y cuarto, el anhelo de formar una familia, aunque antes de ello forjar un patrimonio.

Más allá de lo anterior, es evidente que las relaciones de cathexis, en tanto formas de presión/ deseo cultural para emigrar al norte, como antes se dijo, al menos en la experiencia de Carmelo se construyeron en el marco de un proceso subjetivo donde la necesidad económica, el reto de los amigos para emigrar y la coacción simbólica paterna, fueron un referente de presión cultural, pero de forma simultánea, sentaron las bases para la formación del deseo de emigrar a Estados Unidos, como alternativa viable no sólo para obtener beneficios materiales (como dinero, una casa, etc.) o simbólicos (como prestigio comunitario, relaciones transnacionales, etc.), sino también para ser reconocido como un hombre en la comunidad. 
Caso contrario es el de adolescentes mujeres migrantes como Lucía, una adolescente purépecha de 14 años, procedente de Puruándiro, Michoacán, que también estuvo sujeta a la combinación de presión/deseo cultural por emigrar, pero su situación fue diferente. Para Lucía, la motivación principal fue la invitación de uno de sus hermanos, quien desde hacía años radicaba en Estados Unidos y le propuso que se fuera a vivir con él para que, estando allá, ella estudiara y trabajara. Lucía narró:

Mi hermano tenía cinco años que se había ido al norte, entonces hacía mucho que no lo veía, mi familia no lo veía, pero nos llamaba él, a veces mandaba dinero a mis papás, porque él sabía que no alcanzaba, luego llamó a mis papás y les dijo: Lucía está ya grande, que no siga allí porque no hay futuro verdad, en el pueblo, entonces que se venga conmigo, acá que estudie. Mis papás no querían, porque decían que había peligro, que cómo me iba, ya mi hermano les dijo: "Pues yo le mando dinero para que se venga conmigo, $y$ que vaya con mi amigo para que él la traiga, yo le pago", y mis papás nomás no, más porque ahí la gente decía: "Pero ¿Qué va a hacer allá? Mejor que se quede aquí, ya luego encuentra hombre que la mantenga, para que se arriesga, aquí estudia, ya luego con familia". Mis papás me preguntaron si yo quería irme y les dije que sí, que quería estudiar y trabajar allá en el norte, ya no queriendo me dijeron pues bueno, te vas, y ya mi hermano envió el dinero y su amigo me llevó, acá por Monterrey, luego fuimos a Reynosa y cruzamos, pero la migra nos agarró, ya me enviaron acá y quiero ver a mis papás, aunque me da mucha pena regresar por el qué dirá la gente allá en el pueblo ("Lucía", comunicación personal, 2015).

Como se observa, ni Carmelo ni Lucía lograron el "sueño americano", ya que fueron detenidos por agentes de la Patrulla Fronteriza justo al cruzar el río Bravo. Sin embargo, el simple hecho de haber tomado la decisión de emigrar y hacerlo constituyó un rito, aunque con variaciones de género en términos del reconocimiento social en sus comunidades de origen: mientras que para Carmelo fue bien visto que lo intentó, que tuvo el valor de hacerlo, para Lucía fue una experiencia de fracaso. Al menos para los adolescentes varones, no así en las adolescentes mujeres, la experiencia de emigrar, aunque se haya frustrado, tiene un peso simbólico importante en sus comunidades, pues es reconocido que los hombres tengan el valor de al menos intentarlo. De lo contrario, como mostró Rosas (2007) para el caso de una comunidad veracruzana de migrantes, aquellos hombres que han anunciado que emigrarán y no lo hacen, son seriamente cuestionados por otros hombres y las mujeres, en tanto varones que no tienen palabra ni valor. Al respecto, Rogelio, el joven zapoteco de Oaxaca, comentaba:

Yo me vine con éste (se refería a Gerardo, también de su pueblo), los dos nos animamos, pero pos (sic) este, no nos fue bien. Allá en Santiago hay varios que se han venido, pos por la pobreza, entonces yo y él (Gerardo) les dijimos a nuestros papás que nos veníamos, y ya la familia y la gente supo, ya ni modo de no venir, ya sabían. A mi mamá le había dicho que le iba a mandar dinero, y ya me hacía yo que luego regresaba en una camioneta como otros que llegan así, pero pos no se pudo. Ya ahora que regresemos no sé, qué van a decir, porque luego la gente habla, y nosotros pos sin nada, de vuelta al pueblo, pero al menos lo intentamos, no sé si otra vez se pueda porque no hay dinero y está lejos ("Rogelio", comunicación personal, 2015).

En el relato de Rogelio se puede observar la presión que tuvieron tanto él como su amigo para emigrar a Estados Unidos. Más allá de la pobreza argumentada, el hecho de notificar a sus padres y que parte de la comunidad lo supiera, así como hacer una promesa a su madre, en términos simbólicos constituyó empeñar su palabra y simultáneamente poner su valor a prueba como adolescente que emprenderían un viaje, al estilo de un rito de paso, que lo convertiría en hombre al salir de la comunidad y del país. Por otro lado, la presión se articuló con el deseo de adquirir bienes materiales y, a la vez, el reconocimiento social que tenían otros migrantes de la comunidad.

El dilema cultural que vivía este adolescente indígena en virtud de haber sido detenido y repatriado era, como los demás, el posible estigma al que estaría expuesto al retornar a su comunidad, tanto con su familia como con el resto de la gente, tal como les sucede a migrantes deportados por otras fronteras de México (Albicker, 2014). Sin 
embargo, antes de descubrir lo que sucedería, durante su trayecto a la frontera de Tamaulipas, los adolescentes indígenas entablaron relaciones de poder con otros hombres y mujeres, lo que los situó en un proceso de construcción de género, tal como enseguida se mostrará a través de sus relatos.

\section{Forjando el género en la frontera}

Los adolescentes indígenas entrevistados, tanto los varones como las mujeres, al igual que los mestizos, emprendieron el viaje migratorio desde sus comunidades de origen hasta la frontera de Tamaulipas. Ellos se trasladaron en autobús desde el sur del país hasta la Ciudad de México o bien a la ciudad de Monterrey, y de ahí llegaron a Matamoros o Reynosa, a excepción de José, el adolescente mixteco, cuya ruta migratoria fue distinta, pues de la ciudad de Oaxaca se trasladó a Toluca y posteriormente a Altar, Sonora.

También a excepción de Rogelio y Gerardo, los jóvenes zapotecos, el resto viajaron solos a la frontera; sólo tenían el nombre y teléfono de una persona que contactarían al llegar: los coyotes. La llegada a las ciudades fronterizas significó interactuar con estos actores sociales, pero también con otros migrantes, mexicanos y centroamericanos; vínculos que devinieron en relaciones de poder literales y simbólicas que, en conjunto, forjaron el género con relación a despliegues sustentados en el valor, la discriminación y la competencia, para el caso de los varones; un tipo de "experiencias contradictorias del poder entre los hombres" (Kaufman, 1994), pero también hacia las mujeres.

Respecto al vínculo con el coyote, Lucio, el adolescente purépecha, narraba: "Que llego a la central (de autobuses) y que le llamo (al coyote), me dice que venía por mí y me dio señas (indicaciones). Ya entra y veo un señor con cachucha azul, y me dice: 'Soy yo, vámonos, ipero apúrate!' Que subimos a su carro y manejaba recio, dije: este es un mónharhi (loco) y me dio un poco de miedo, pero llegamos a una casa y ahí estuvimos". Gerardo, por otra parte, relataba: "En la casa que nos llevó (el coyote) estuvimos más de un día, dentro nos decía: '¡Órales, cabrones, no hagan ruido!' A los que no eran mexicanos, como hablaban diferente, les gritaba y a éste (Rogelio) y a mí, como nos escuchó hablar la lengua (zapoteca), que dice: ‘¡ya cállense, pinches indios! Y pues me asusté"”.

Al menos en los relatos expuestos, son evidentes las relaciones de poder que se tejieron entre los coyotes y los adolescentes varones indígenas. No en balde, el mismo Kaufman (1994) afirmó que "el rasgo común de las formas dominantes de la masculinidad contemporánea es que se equipara el hecho de ser hombre con tener algún tipo de poder" (p. 143). Exigirles a los adolescentes que se apuraran, manejar recio, mantenerlos enclaustrados, gritarles e insultarlos constituían tan sólo algunas formas de relaciones de poder que ejercieron los coyotes, legitimando una masculinidad dominante sobre una subordinada, sustentada esta última en la vulnerabilidad migrante y étnica.

Las adolescentes migrantes no fueron la excepción: ellas también fueron objeto de escarnio por parte de los coyotes, pues al igual que a los adolescentes varones, les gritaban y las insultaban llamándolas "indias", porque las veían morenas y de estatura baja. Martha, la adolescente mixteca, comentaba al respecto: "El hombre ese nos gritaba, y como nos veía a varios morenos y sabía que éramos de allá de Oaxaca o de Chiapas, nos decía indios, también a la gente que venía de Guatemala y de otras partes, los trataba mal, aunque no nos golpearon o otra cosa, pero sí nos daba miedo porque gritaba feo el hombre ese". La narrativa de Martha fue similar a la de Tomasa, la adolescente zapoteca también de Oaxaca: "A mí donde estuve, nos llevó un señor a una casa, estaba lejos y nos preguntaba de donde era, luego llegó otro y se reía muy feo cuando nos miraba a todos, a mí me asustaba porque era feo, luego trataba mal a la gente hasta ya que tuvimos que irnos, porque nos decía que parecíamos changos, no sé por qué".

En los relatos, como se observa, también es posible captar el miedo/susto como una dimensión subjetiva de los adolescentes indígenas, la cual en gran medida legitimó las relaciones de poder que vivieron con los coyotes. El miedo (chéta en purépecha) y el susto o estar asustado (cadxibe' en zapoteco), irónicamente pusieron a prueba el valor de los adolescentes al encontrarse con los coyotes en la central de autobuses o las "casas de seguridad", respectivamente, pues ello significó adentrarse en 
lo que Miedzian (1995) ha llamado "mística de la masculinidad", la cual se constituye por valores como la dureza y la represión de la empatía, entre otros; mística que, evidentemente, también puede ser femenina, o de género, pues tanto los adolescentes varones como las mujeres, pusieron a prueba su valor, dureza y otras cualidades para la sobrevivencia.

En dicha mística de género, articulada con relaciones de poder, no sólo se vieron involucrados los adolescentes indígenas con los coyotes, sino también con otros migrantes, tanto hombres como mujeres, mexicanos y centroamericanos, al permanecer en las "casas de seguridad". Aunque dentro de ellas las y los migrantes en conjunto vivieron una violencia simbólica al experimentar el encierro y sujetarse a reglas impuestas por los coyotes (Hernández-Hernández, 2016), entre ellos se generaron disputas en torno al espacio, el control grupal y las relaciones entre los sexos, tal como lo narró José, el adolescente mixteco, durante la entrevista:

$O .:$ ¿Y qué fue lo que pasó en la casa esa que dices que estuvieron?

José: Estuvimos bastante, más de un día, encerrados, nos llevaban que sopa, tortillas y a veces pollo y agua, pero poco, entonces estábamos ahí, ¿verdad? Con el señor ese cuidando y a veces salía, nos decía que no hiciéramos ruido.

O.: ¿Había otros chicos como tú en la casa?

José: $\mathrm{Si}$, habíamos muchos, otros que venían de más allá de Chiapas, que hablaban español pero diferente, ¿verdad? Eran grandes y este comenzaban a decir que nos hiciéramos más para allá, porque la casa era chica, con dos cuartos, entonces decimos unos: ¿Pues para dónde? Y estos que se enojan y dicen: "Que te vamos a cachimbear pues, si no te mueves", entonces pues unas muchachas jarochas ya dicen: "Oigan, ya, no hay espacio, pero nos hacemos acá”.

$O .:$ ¿Y siguieron molestos?

José: Ya este las muchachas les dicen eso a los muchachos y este que les gritan, que no se metiera, que ellos habían pagado mucho, y dicen las muchachas: "pues nosotras también", en eso que regresa el señor ese y se calmaron, que dice: "QQué pasa aquí? Les dije que no hicieran ruido" (“José”, comunicación personal, 2015).
La narrativa de José deja entrever otros matices de las relaciones de poder que se tejieron entre los propios migrantes, particularmente orientadas al intento de control de algunos varones jóvenes (en este caso de Guatemala) hacia los adolescentes indígenas y las mujeres mestizas de Veracruz. De cierta forma, este episodio deja entrever cómo algunos varones intentaron legitimarse como hombres dominantes ante otros cuya edad y etnicidad los hacía vulnerables, pero también un intento de legitimación ante las mujeres, sin importar la nacionalidad. No obstante, los adolescentes indígenas al igual que los/las otros/otras migrantes, vivieron una última situación en la que fueron puestos a prueba en el marco de ideologías y relaciones de género.

En concreto, se trató de salir de las "casas de seguridad" y cruzar el río Bravo para internarse en Estados Unidos. Los adolescentes indígenas sabían que al cruzar el río estaban expuestos a ahogarse, tal como ha sucedido en innumerables casos que han documentado los medios de comunicación, pero ello podía pasar siempre y cuando no supieran nadar, pues en su opinión saber nadar les daba una ventaja relativa para cruzar, a diferencia de otros que no tenían esta habilidad.

Quienes sabían nadar, cruzaron el río Bravo con relativa facilidad. Los relatos de algunos adolescentes indígenas oscilan entre la presunción y el miedo, narrando que en virtud de que algunos aprendieron esta habilidad en sus lugares de origen y el río no es tan grande como otros que han conocido, les fue sencillo cruzarlo en comparación con quienes no sabían nadar. Al respecto, Carmelo comentó: "Para mí fue fácil cruzar, es que yo sé nadar, entonces el río como es chico, pues no me fue difícil, tampoco me dio miedo, había otros que no sabían y esos sí batallaron o los tuvieron que ayudar".

Durante las entrevistas, además, una de las interrogantes que surgió fue si los adolescentes indígenas tuvieron miedo al cruzar la frontera. Lucio, por ejemplo, comentó al respecto: “No, no me dio miedo, ¿así como que me fuera a ahogar o a pasar algo? No, para nada, yo iba tranquilo, lo que me preocupaba es que nos agarrara la migra". Narrativas como la de Lucio ponen de relieve que, al cruzar, además, los adolescentes varones reforzaron 
su masculinidad al hacer algunos alardes de hombría (Hernández-Hernández, 2012), no sólo ante aquellos adolescentes varones -indígenas y mestizos, nacionales y extranjeros- que no sabían nadar, sino también ante las mujeres independientemente de si tenían o no dicha habilidad.

Claramente, este último fue el caso de los adolescentes indígenas que tenían la habilidad de nadar. Por el contrario, aquellos que no sabían, específicamente algunos de los mestizos, además de incrementarse el riesgo de ahogarse en el río Bravo, estuvieron sujetos al estigma por parte de otros migrantes que cruzaban, tanto jóvenes como adultos, e incluso de los coyotes, porque tenían que recibir apoyo al igual que las mujeres o los adultos mayores que no sabían nadar.

Al respecto, José comentaba que una de las estrategias que usan los coyotes para lograr cruzar a todos/todas los/las migrantes es dividirles entre quienes saben nadar y quienes no saben. Al adentrarse en el río, parte de quienes saben nadar son colocados al frente, y otra parte como apoyo para quienes no saben nadar, a decir de algunos menores de edad, mujeres y ancianos que colocan en cámaras infladas. En otras palabras, cruzar el río Bravo también responde a una ideología de género que coloca al frente a los varones migrantes con habilidad para nadar, bajo el supuesto de que son ellos un soporte importante para los y las débiles, a decir de mujeres y ancianos que requieren de apoyo para cruzar la frontera.

Esta situación, al menos para los migrantes que no saben nadar y son puestos en las cámaras inflables, los pone en una situación de vergüenza y estigma que toleran, porque sólo tienen un objetivo en mente: lograr cruzar el río sin ahogarse y sin hacer ruido. Aunque José sabía nadar, hablaba de esta situación tanto en su experiencia como en la de otros: "Ya que íbamos a meternos al río, el coyote nos preguntó si sabíamos nadar y yo le dije que sí. La verdad me daba miedo ahogarme, pero entonces les dice a otros que no sabían: 'Ustedes se van a agarrar de esta cámara, aquí con las señoras'. Eso les daba pena, más porque otros se reían, pero fueron varios". Sobre la misma experiencia de cruzar el río Bravo, Tomasa comentaba:
A mí me pusieron a lado de una cámara inflable, aunque yo sí sé nadar, pero como me veían chica no me creían, entonces dice el coyote: 'tú te vas ahí, pegada de la cámara con las otras mujeres, no te me vayas a ahogar'. Que le digo: 'pero sí sé', y que me dice: ‘¡No! Te vas ahí, al frente van los hombres que saben nadar'. Y así puso a otras mujeres en las cámaras y algunos muchachos que no nadaban, entonces iban callados y el coyote se reía de ellos ("Tomasa", comunicación personal, 2015).

Como se pudo apreciar, cruzar la frontera por el río Bravo constituyó un riesgo para los adolescentes migrantes en general, dado que representó poner a prueba su habilidad para nadar o no ahogarse. Sin embargo, cruzar el río también representó un ritual de género en el que la masculinidad fue legitimada o denigrada, mientras que la feminidad fue la base para lograrlo. En esta situación, como se señaló, los adolescentes indígenas demostraron no sólo su habilidad para nadar, sino también una mezcla de valor y miedo que les dotó de cierto reconocimiento social ante los coyotes y otros migrantes mestizos al cruzar la frontera. Por el contrario, las adolescentes migrantes, aún teniendo la misma habilidad, fueron denigradas por el sólo hecho de ser mujeres e indígenas.

\section{Conclusiones}

El objetivo de este trabajo fue presentary analizar las experiencias migratorias de algunos adolescentes indígenas mexicanos y analizar las narrativas de género subyacentes en dichas experiencias. Por supuesto, se trató de los casos particulares de nueve adolescentes de ambos sexos, oriundos del sur y centro occidente de México, procedentes de diferentes grupos étnicos, y específicamente, de adolescentes cuyas experiencias migratorias se remiten a sus viajes hasta la frontera, y no viviendo "aventuras en el norte" como los menores que Ruehs (2016) estudió, pues ellos fueron detenidos al cruzar la frontera México-Estados Unidos y repatriados.

Los referentes teóricos orientados a concebir el género un elemento constitutivo de las relaciones sociales entre los sexos y, específicamente, como relaciones de poder (Scott, 1996), así como el género 
como una forma de ordenamiento de la práctica social también a través de relaciones de poder cotidianas (Connell, 1997), permitieron captar, en primer lugar, que al menos en las comunidades de origen de los adolescentes indígenas existe una configuración étnico-cultural moldeada por ideologías y relaciones de género sui géneris. De cierta forma las cosmovisiones locales en torno a lo masculino y lo femenino han devenido en una clara diferenciación de las posiciones de hombres y de mujeres, así como en la división sexual del trabajo.

Esto se traduce en la existencia de relaciones de poder y de producción particulares en las comunidades de los adolescentes indígenas, lo cual es relevante para comprender, en parte, por qué optaron por emigrar: ante las carencias económicas, su posición como hijos mayores o bien la ausencia paterna en algunos casos, ellos asumieron la responsabilidad moral de ser los proveedores económicos de la familia. O bien, en el caso de las adolescentes mujeres, ellas también asumieron cierta responsabilidad familiar, aunque con un abanico de cuestionamientos étnicos y de género.

Pero no sólo eso, pues la indagación también muestra que relaciones de cathexis tuvieron que ver en la toma de decisión para emigrar por parte de los adolescentes, tanto varones como mujeres, las cuales se matizaron en formas de presión/deseo cultural para emigrar, mismas que emergieron de un proceso subjetivo donde la necesidad, el reto de los amigos y en parte la coacción simbólica paterna, de amigos o hermanos mayores, fueron un referente importante.

Por supuesto, de fondo, la idea de emigrar a Estados Unidos era obtener beneficios tanto materiales como simbólicos, pero también para ser reconocidos como hombres o mujeres en sus comunidades de origen. No obstante, como lo muestran los relatos, durante su viaje a la frontera $\mathrm{y}$ estancia en la misma, ellos se enfrentaron a ideologías y relaciones de género insertas en relaciones de poder, tanto con otros hombres como con las mujeres, mestizos/as o indígenas, o más específicamente, su estancia en la frontera constituyó un rito de paso en las que se vieron inmersos en una mística de la masculinidad (Miedzian, 1995) y más ampliamente en una mística de género, en especial al confrontar su valor-miedo con los coyotes y otros/ otras migrantes, en diferentes espacios y situaciones de interacción.

Claro está, durante este proceso es evidente que al menos entre los adolescentes indígenas la construcción de ideologías y relaciones de género se dio al ponerse a prueba entre sí, ante varones mestizos, de diferentes edades y nacionalidades y también ante las mujeres, ya fuera que estuvieran en casas de seguridad o cruzando el río Bravo; por otro lado, la construcción de género entre ellos y ellas también se vio articulada con expresiones de violencia -literal y metafórica- que les vulneró dada su posición como migrantes y adolescentes, además como indígenas que transitaban en una región fronteriza desconocida y entre personas mestizas.

Sin duda, el estudio de caso presentado contribuye a los estudios de género en la migración transnacional de la niñez, un campo emergente y crítico, tal como hace un lustro lo definió Hondagneu-Sotelo (2011). De igual forma, aporta al llamado de estudiar la construcción del sujeto indígena contemporáneo, como enfatiza DíazCervantes (2014) a propósito de hacer análisis que articulen etnicidad, género e incluso migración. No obstante, el estudio presentado también da pie para pensar en otras vetas de investigación y reflexión que aquí no fueron abordadas.

La primera de ellas es la relacionada con lo que se ha denominado antropología de las emociones (Bourdin 2016), la cual postula indagar su variabilidad cultural. Aunque en el ámbito de los estudios sobre migración dicha propuesta ha tenido cierta acogida, principalmente a estudiar las experiencias de mujeres centroamericanas, en el campo de los estudios sobre niñez, adolescentes o jóvenes migrantes no ha sido así. En particular sería relevante conocer qué emociones despliegan los adolescentes migrantes al retornar a sus comunidades de origen, en particular cuando la experiencia migratoria ha sido de fracaso, sobre todo, cómo dichas emociones son configuradas o significadas por familiares y pares, y simultáneamente, cómo éstas redefinen sus nociones sobre ser un hombre, en especial en el marco de sus culturas étnicas.

De forma paralela, también sería relevante el análisis de las experiencias de aquellos adolescentes 
indígenas que no han emigrado, a pesar de residir en comunidades pobres o expulsoras de migrantes. $\mathrm{Si}$ bien en comunidades rurales de México -mestizas e indígenas- la migración transnacional ha propiciado una serie de transformaciones económicas y culturales, tales como reforzar el mandato masculino de proveer, controlar a las mujeres y sentirse valiente, como señala Rosas (2007), la exploración de las experiencias de aquellos varones que deciden no emigrar o que aún no lo hacen permitiría conocer formas alternativas de ser un hombre, de confrontar los cuestionamientos patriarcales, en especial entre adolescentes y jóvenes indígenas mexicanos.

Finalmente, una veta que en este estudio quedó ausente es la relacionada con la etnicidad. Aunque se trató de adolescentes indígenas migrantes, dicha categoría de análisis no se privilegió puesto que el énfasis fue en las experiencias migratorias y las narrativas de género, pero también porque la etnicidad, como concepto, está sujeta a enfoques múltiples e incluso contradictorios (Restrepo, 2004). No obstante, en tanto una forma de identificación étnico-cultural, fue evidente que los/ las adolescentes migrantes expresaban sentidos de pertenencia, e incluso de denigración y exclusión por el hecho de ser indígenas, además de migrantes en tránsito expuestos a riesgos.

\section{Referencias bibliográficas}

Albicker, Sandra. (2014). Identidades narrativas y estigma: deportados en el Bordo de Tijuana (Tesis de maestría). El Colegio de la Frontera Norte, Tijuana, México.

Aquino, Alejandra. (2009). Entre el "sueño zapatista" y el "sueño americano": la migración a Estados Unidos vista desde las comunidades zapatistas. Migración y Desarrollo, 13, 13-21.

Aquino, Alejandra. (2012). La migración de jóvenes zapatistas a Estados Unidos como desplazamiento geográfico, político y subjetivo. European Review of Latin American and Caribbean Studies, 92, 3-22.

Ariza, Marina. (2014). Migration and Family in Mexican Research: A Recent Appraisal. Migraciones Internacionales, 7(4), 9-37.

Askew, Sue y Ross, Carol. (1991). Los chicos no lloran. El sexismo en educación (Luis Botella, Trad.). Barcelona: Paidós Ibérica.

Bertaux, Daniel. (2005). Los relatos de vida. Perspectiva etnosociológica (Godofredo González, Trad.). Barcelona: Ediciones Bellaterra. (Obra original publicada en 1997).

Bourdin, Gabriel. (2016). Antropología de las emociones: conceptos y tendencias. Cuicuilco. Revista de Ciencias Antropológicas, 23(67), 55-74.

Castellanos, Gabriela. (2003). Sexo, género y feminismo: tres categorías en pugna. En Marta Cardona y Patricia Tovar (Ed.), Familia, género y antropología. Desafios y transformaciones (pp. 30-65). Bogotá: ICAHN.

Connell, Robert. (1997). La organización social de la masculinidad. En Teresa Valdés y José Olavarría (Eds.), Masculinidad/es. Poder y crisis (pp. 31-48). Santiago de Chile: Isis Internacional.

Cruz, Tania. (2015). Experimentando California: cambio generacional entre tzeltales y choles de la selva chiapaneca. Cuicuilco, 62, 217-229.

Chávez, Lilian y Menjívar, Cecilia. (2010). Children without Borders: A Mapping of the Literature on Unaccompanied Migrant Children to the United States. Migraciones Internacionales, 3(5), 71-111.

De Barbieri, Teresita. (1995). Certezas y malos entendidos sobre la categoría de género. En Laura Guzmán y Gilda Pacheco (Comps.), Estudios básicos de derechos humanos IV (pp. 32-62). San José: Instituto Interamericano de Derechos Humanos.

Díaz-Cervantes, Rufino. (2014). La perspectiva de género en la construcción de la masculinidad y la sobrevivencia indígena en México. Agricultura, Sociedad y Desarrollo, 3(11), 359-378.

Díaz, Víctor y Calzadilla, Aracelis. (2016). Artículos científicos, tipos de investigación y productividad científica en las Ciencias de la Salud. Revista Ciencias de la Salud, 14(1), 115-121.

Hernández, Ernesto. (2008). Entre la memoria y el olvido: padres migrantes indígenas. En Juan Ramírez y Giselda Uribe (Coords.), Masculinidades. El juego de los hombres en el que participan las mujeres (pp. 201-216). México: Plaza y Valdés.

Hernández-Hernández, Oscar. (2012). Migración, masculinidad y menores repatriados por la frontera Matamoros-Brownsville. Trayectorias, 14(33-34), 76-94.

Hernández-Hernández, Oscar. (2016). Migrant Children and Safe Houses in the Tamaulipas-Texas Border Region. En Milo Kearney, Anthony Knopp, Antonio Zavaleta y Thomas Knighteditors (Eds.), Extra Studies in Rio Grande Valley History (pp. 329-346). Texas: The University of Texas Rio Grande Valley.

Hondagneu-Sotelo, Pierrette. (2011). Gender and Migration Scholarship: An Overview from a $21^{\text {st }}$. Century Perspective. Migraciones Internacionales, 1(6), 219-233.

Huacuz, María y Barragán, Anabella. (2008). Cruzar la frontera: La migración internacional como rito de construcción de la masculinidad en jóvenes de 
Guanajuato. La Manzana. Revista Internacional de Masculinidades, 5(3). Recuperado de http://www. estudiosmasculinidades.buap.mx/num5/jovenes. html.

Kaufman, Michael. (1994). Men, feminism, and men's contradictory experiences of power. En Harry Brod y Michael Kaufman (Eds.), Theorizing Masculinities (pp. 59-85). California: SAGE Publications.

López, Martín. (2010). Hacerse hombres cabales. Masculinidad entre tojolabales. México: CIESAS.

Martínez, Luis. (2010). La dinámica comunitaria vista desde la migración en la sierra nahua de Zongolica, Veracruz: análisis y perspectivas de estudio. Migraciones Internacionales, 4(5), 9-37.

Maturano, Alejandro. (2010). Danza de Tecuanes de Acatlán de Osorio, Puebla, 24 de octubre [Blog]. Recuperado de http://danzaytradiciondemexico. blogspot.mx/2010/03/danza-de-tecuanes-de-acatlande-osorio.html.

Miedzian, Myriam. (1995). Chicos son, hombres serán. ¿Cómo romper los lazos entre masculinidad y violencia? Madrid: Horas y horas.

Moctezuma, Miguel. (2014). Más allá de los menores migrantes "no acompañados". Políticas públicas y alternativas transnacionales. México: Universidad Autónoma de Zacatecas.

Navarrete, Federico. (2008). Los pueblos indígenas de México. Pueblos indígenas del México contemporáneo. México: Comisión Nacional para el Desarrollo de los Pueblos Indígenas.

Nolasco, Margarita y Rubio, Miguel. (2005). La migración indígena: causas y efectos en la cultura, la economía y la población. En Séptima Reunión Nacional de Investigación del Proyecto Etnografía de las Regiones Indígenas de México ante el Nuevo Milenio. Ponencia presentada en el Instituto Nacional de Antropología e Historia, México.

Núñez, Guillermo. (2007). Vínculo de pareja y hombría: "atender y mantener" en adultos mayores del Río Sonora, México. En Ana Amuchástegui e Ivonne Szasz (Coords.), Sucede que me canso de ser hombre... Relatos y reflexiones sobre hombres $y$ masculinidades en México (pp.141-184). México: El Colegio de México.

Pries, Ludger. (2002). La migración transnacional y la perforación de los contenedores de Estados-nación. Estudios Demográficos y Urbanos, (51), 571-597.

Ramírez, David; Gutiérrez, Servando; Valladares, Clara y Gutiérrez, Adriana. (S.f.). Referentes masculinos y opiniones acerca de la paternidad en jóvenes indígenas y no indígenas de la región Otomí-Tepehua, Hidalgo-México: ¿Reconfigurando un modelo hegemónico? Recuperado de https://bit.ly/2Olrxui.

Randall, Margaret. (1992). ¿Qué es y cómo se hace un testimonio? Revista de Crítica Literaria Latinoamericana, (36), 221-245.

Restrepo, Eduardo. (2004). Teorías contemporáneas de la etnicidad. Stuart Hall y Michel Foucault. Colombia: Editorial Universidad del Cauca.

Rosas, Carolina. (2007). El desafío de ser hombre y no migrar. Estudio de caso en una comunidad del centro de Veracruz. En Ana Amuchástegui e Ivonne Szasz (Coords.), Sucede que me canso de ser hombre... Relatos y reflexiones sobre hombres y masculinidades en México (pp. 275-310). México: El Colegio de México.

Ruehs, Emily. (2016). Adventures in El Norte: Masculinity and the Immigration of Unaccompanied Minors. Men and Masculinities, 20(3), 364-384. doi: 10.1177/1097184X16634796.

Ruiz, Olivia. (2001). Los riesgos de cruzar: la migración centroamericana en la frontera México-Guatemala. Frontera Norte, 13(25), 7-41.

Scott, Joan. (1996). El género: una categoría útil para el análisis histórico. En Marta Lamas (Comp.), El género: la construcción cultural de la diferencia sexual (pp. 265-302). México: Programa Universitario de Estudios de Género, Universidad Nacional Autónoma de México.

Smith, Robert. (2006). Mexican New York. Transnational Lives of New Inmigrants, Berkeley: University of California Press.

Stephen, Lynn. (2002). Sexualities and Gender in Zapotec Oaxaca. Latin American Perspectives, 29(2), 41-59.

Stern, Steve. (1999). La historia secreta del género. Mujeres, hombres y poder en México en las postrimerías del periodo colonial (Eduardo Suárez, Trad.). México: Fondo de Cultura Económica.

Tomás, Casimiro. (2013). La diáspora transnacional purépecha en Estados Unidos. Acta Universitaria, 23(1), 59-67.

Torres, Alicia y Carrasco, Jesús (Coords.). (2008). Al filo de la identidad. La migración indígena en América Latina. Quito: FLACSO Ecuador.

Villanueva, Daniel y García, María. (2008). Algunas causas de la migración internacional en Chiapas. Economía y Sociedad, 14(21), 41-58.

Weissmann, Patricia. (2005). Adolescencia. Revista Iberoamericana de Educación, 35(6). Recuperado de https://rieoei.org/historico/ deloslectores/898Weissmann.PDF.

\section{Fuentes primarias}

"Carmelo", 16 años, comunicación personal, 2015. Proyecto: Violación de derechos humanos de menores migrantes no acompañados en la frontera de Tamaulipas, México.

“José”, 17 años, comunicación personal, 2015. Proyecto: 
Violación de derechos humanos de menores migrantes no acompañados en la frontera de Tamaulipas, México.

"Lucía", 14 años, comunicación personal, 2015. Proyecto: Violación de derechos humanos de menores migrantes no acompañados en la frontera de Tamaulipas, México.

"Lucio", 16 años, comunicación personal, 2015. Proyecto: Violación de derechos humanos de menores migrantes no acompañados en la frontera de Tamaulipas, México.
"Martha", 14 años, comunicación personal, 2015. Proyecto: Violación de derechos humanos de menores migrantes no acompañados en la frontera de Tamaulipas, México.

"Rogelio", 16 años, comunicación personal, 2015. Proyecto: Violación de derechos humanos de menores migrantes no acompañados en la frontera de Tamaulipas, México.

"Tomasa", 15 años, comunicación personal, 2015. Proyecto: Violación de derechos humanos de menores migrantes no acompañados en la frontera de Tamaulipas, México. 